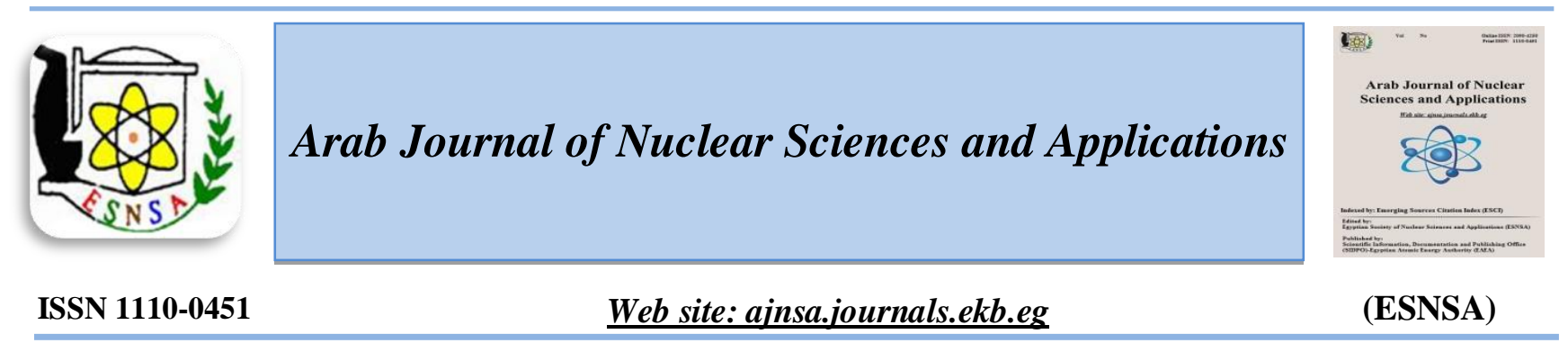

\title{
First Trial to Assess Gamma-Irradiation and Diatomaceous Earth Combination on Mortality of some Stored Product Insects
}

\author{
Th. M. Sileem ${ }^{(1)}$,S. A.Mohamed ${ }^{(2)}$ and A. L. Mehany ${ }^{(2)}$ \\ ${ }^{(1)}$ Biological Application Department-Nuclear Research Center-Atomic Energy Authority Cairo, Egypt \\ ${ }^{(2)}$ Plant Research Department- Nuclear Research Center -Atomic Energy Authority, Cairo, Egypt
}

Received $10^{\text {th }}$ Nov. 2018 Accepted $17^{\text {th }}$ Apr. 2019

This study was designed to characterize the combination of gamma-irradiation and food grade diatomaceous earth(Wolf Creek ranch, California, USA) as diatomaceous earth formulation (DE) treatment against three of stored product insect pests [Sitophilusgranarius $(\mathrm{L})$, Triboliumcastaneum(Herbst.) and Rhyzoperthadominica,(F)]in the laboratory. The study was assessed the killing effect of $\gamma$-irradiation at $0,50,100$ and 250 Gray against these pests. As well as $0,0.5,1.0$ and 1.5 $\mathrm{g} / \mathrm{kg}(\mathrm{w} / \mathrm{w})$ concentrations of $\mathrm{DE}$ formulation alone or in combination with irradiation were assessed. The obtained results indicated that the mixing between two insect control methods had the combined advantages of quick speed of killing and a high level of safety. Where, the $\mathbf{L T}_{\mathbf{5 0}}$ have a wide range of values and the combined treatments of $\gamma$-irradiation and treatment with DE maybe were the most influencing factors reducing lifespan after treatments. In this laboratory study the combination between DE $(1 \mathrm{~g} / \mathrm{kg})$ and irradiated the tested pests with $(100 \mathrm{~Gy})$ of gamma ray produced a potentiation and additive interactions in the case of $T$. castaneumandR.dominica $F$ adults, while the same combination produced an antagonistic interactionin the case of $S$. granariusadults. Our finding stated that the use of 'control method' $\gamma$-irradiation in conjunction with DE could be a feasible strategic component in Insect Pest Management; IPM in operational modality might be 'sequential' against the tested pests. That is to apply irradiation to eliminate existing census personnel. This is then followed by the addition of DE to the grain to prevent the re-infestation.

\section{Keywords: Gamma-irradiation/ diatomaceous earths (DEs)/Insect management}

\section{Introduction}

Stored product pests cause serious damage both in quantity and quality of crop whereas; the pest infestations reduce the value of the commodity by contaminating it with insect fragments, feces, webbing, and metabolic by-products [1]. The postharvest losses in storage, estimated about $20 \%$ or more in developing countries [2]. Confronted with increasing problems of stored-product protection with synthetic pesticides (pests resistance, harmful impact on health and environment, pesticides residues), there is a growing requisite for safer methods in stored-pests control. A combination of control tactics for protecting stored products, such as an Integrated Pest Management (IPM) program, has recently been considered. Insecticide mixtures are now commonly used to control multiple and resistant insect pests. Where, the use of potentiation mixtures is a useful strategy to combat insecticide resistance. One of the basic methods for stored-product protection is ionizing radiations like $\mathrm{X}$-rays and gamma rays $[3,4]$.

Interest in the use of irradiation as a phytosanitary treatment for agricultural commodities is growing worldwide, particularly since the publication of the International Plant Protection Convention (IPPC) standard that endorses and facilitates trade based on this disinfestations method [3, 5]. Another

Corresponding author: thanaasileem@yahoo.com

DOI: $10.21608 / a j n s a .2019 .6159 .1134$

(C) Scientific Information, Documentation and Publishing Office (SIDPO)-EAEA 
potential alternative is the use of desiccant dusts; particularly diatomaceous earths (DEs) which have low mammalian toxicity, can easily be removed from the grain before milling and providing longterm effectiveness [6,7]. So far, the combination of DEs with gamma-irradiation against the insect pests has not yet been studied. Insects exposed to DE combined with other insecticides may either reduce the amount of DE needed to control stored grain insects or produce synergistic effects. Our objective is to evaluate the efficacy and examine potential synergistic effects of gamma-irradiation processing combined with DE treatment against some stored-product species, the lesser grain borer Rhyzoperthadominica, F. the grain weevil SitophilusgranariusL. and the red flour beetle Triboliumcastaneum(Herbst.).

\section{Materials And Methods}

\section{Insect cultures}

Astock cultures of RhyzoperthadominicaF., SitophilusgranariusL and Triboliumcastaneum(Herbst.) were obtained from Unit of Stored Products, Biological Application Department, Nuclear Research Center, Abu Zaabal, Egypt. Test insects, S. granarius and R.dominica were bred on hard wheat with approximately $13 \%$ moisture content (m.c.) and on whole wheat flour with brewer 5\% un-activated yeast for $T$. castaneum, all under controlled circumstances, at $30 \pm 2{ }^{\circ} \mathrm{C}$ and $70 \pm 5 \% \mathrm{RH}$.

\section{Assessing the effect of gamma irradiation on the insect pests}

Samples of 1- week old adults of various insects were irradiated at doses of 50, 100 and 250 gray (Gy), with gamma rays. Irradiation doses were selected based on previous studies [8, 9]. Irradiation was performed in the Cyclotron Project, Nuclear Research Centre, Abu Zaabal, Egypt, using Cobalt-60 (Co-60)gamma cell; the dose rate of irradiation source was 0.37 Gray/ second. After irradiations, the insects were kept in the rearing jars with their diets and adult mortality was monitored daily over 7 days after the treatment, the accumulative mortality was counted. Insects were considered dead if they did not respond to three probing of a blunt probe. Three replicates (20 adult per replicate) were used for each tested pest for dose level and control.

\section{Assessing the effect of diatomaceous earth on the insect pests}

The diatomaceous earth DE formulation which used is food grade diatomaceous earth (Wolf Creek ranch, California, USA) The DE of freshwater fossil shell (contains 89\%) silicon dioxide was grounded into fine powder. Glass jars of $200 \mathrm{ml}$ were filled with 20 grams of wheat or wheat flour with brewer $5 \%$ un-activated yeast determined concentrations of $0.01,0.02$ and $0.03 \mathrm{~g}$ of $\mathrm{DE} / 20 \mathrm{~g}$ insect diet $(0.5, \quad 1.0$ and $1.5 \mathrm{~g} / \mathrm{Kg})$. These concentrations were selected based on previous studies $[10,11]$. The jars were tightly closed with the lids and thoroughly shaken by hands for 30 seconds in order to have equally dusts distribution through the grains. Jars with untreated grain served as control. After dust was settled down, 20 unsexed, one week old adults of each insect species were added into each jar. All treatments were conducted in 3 repetitions. Mortality was expressed as percentage of dead adults on the total number of beetles found in each jar after 7days from initial treatment. The observation period was chosen to prevent both of the increasing damage of stored product resulting of insect consumed and the replacement of new emergence insects resulting of egg lying.

Joint action of gamma irradiation with diatomaceous earth treatment

The combined effects studies of gamma irradiation were performed with the dose of $100 \mathrm{~Gy}$ because it is the appropriate intermediate dose for all testing insects, and the concentration of $1 \mathrm{~g} / \mathrm{kg}$. The bioassay was undertaken as follows, treatment (1): gamma-irradiation at a chosen dose was followed by treated with diatomaceous earth at chosen concentration after $24 \mathrm{~h}$ from irradiation. Treatment (2): gamma- irradiation at a chosen dose was preceded by diatomaceous earth at chosen concentration. In Both treatments, observations on the mortality were recorded after $24 \mathrm{~h}$ from treatment until 7 days. Then, the median lethal time $\left(\mathrm{LT}_{50}\right)$ was calculated in all treatments, each treatment was repeated three times with 20 insects per replicate. The combined (joint) action of the combinations was presented as Co-toxicity factor to distinguish among potentiation, antagonism and additive [12], by applying the formula given below:

Co-toxicity factor $=\frac{\text { Observed } \% \text { mortality }- \text { expected } \% \text { mortality } \times 100}{\text { Expected } \% \text { mortality }}$

The expected mortality for the mixture of two treatments was the sum of the mortalities of each 
concentration used in the mixture. This factor was used to categorize the results into three categories as follow : Co-toxicity factors $\geq \quad+20$ meant potentiation; $\quad$ co-toxicity factors $\leq-\quad 20$ meantantagonism; and co-toxicity factors between -20 and +20 meant additive effect.

\section{Data analysis}

The data were analyzed by one-way ANOVA, using the GLM procedure of SPSS 17.0. Mean separation within columns by Duncan's multiple range test and the same letter are not significantly different at $P<0.05$. Mortality rate data were corrected for control mortality using Abbott's formula [13], the arcsine square-root being transformed before analysis. The data are presented as untransformed means. The median lethal time $\left(\mathrm{LT}_{50}\right)$ values were assessed by Probit analysis [14].

\section{Results}

Effect of gamma-irradiation on the insect pest mortality

To determine the gamma irradiation effects on the mortalities of various insect pests, adult stage of each specieshave been treated at $0,50,100$ and 250 Gy. For T. castaneum the mortality percentages were $3.3,16.7,23.0$ and $36.7 \%$ as shown respectively, for doses $0,50,100$ and 250 Gy (Figure1). The mortality were 6.7, 60.0, 66.7 and $83.3 \%$ for doses 0, 50, 100 and 250 Gyfor irradiated S. granariusL. and $0,6.7,13.3$ and $13.3 \%$ for irradiated R. dominica. Adults of S. granariusL were the most sensitive to the treatment. This caused significantly more mortality from control after the 7 days observation period ( $\mathrm{df}=3, \mathrm{~F}=85.6$ and $\mathrm{P}<0.001$ ). While $R$. dominica $\mathrm{F}$. showed more tolerant to radiation doses than other pests. The irradiation is consideredas a pest control measure, because it kills most pests at the doses commonly used.

\section{Effect of diatomaceous earth treatment on the insect pest mortality}

The accumulative mortality percent of weevils and beetles after 7 days of exposure to diatomaceous earth varied with insect species and concentrations used (Figure2). The lowest insecticidal efficacy of DE was recorded against T. castaneum (Herbst) adults where, the percentages of mortality were $40.0,43.3$ and $46.7 \%$ at $0.5,1.0$ and $1.5 \mathrm{~g} / \mathrm{kg}$ concentrations. S. granaries was the most susceptible to DE treatment where, the accumulative mortality percents were respectively, for the same DE doses57.5, 64.2 and 75.7\%.

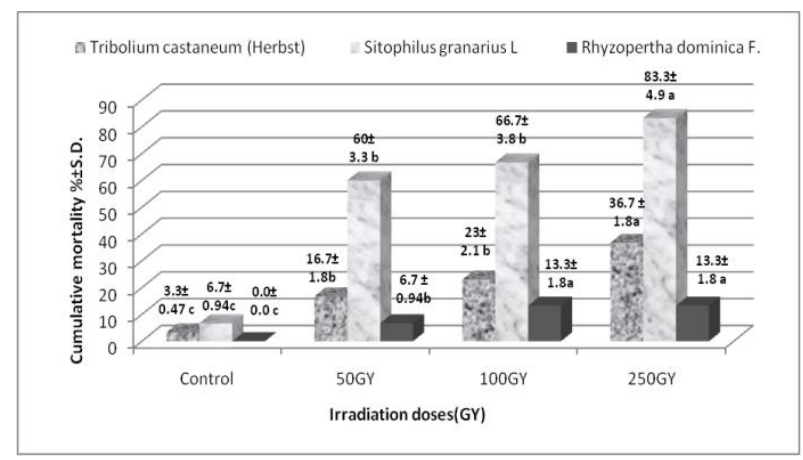

Figure (1): Effect of gamma-irradiation on cumulative mortality percentages of different stored products pests at $7^{\text {th }}$ day from irradiation

Joint action of gamma irradiation with diatomaceous earth treatment

The joint toxic action of gamma-irradiation at dose of 100 Gy with the tested diatomaceous earth at $1 \mathrm{~g} / \mathrm{kg}$ concentration for two combination types is presented in Table (1). Our hypothesis was that the presence of irradiated insects on wheat mixed with diatomaceous earth treatment would increase the killing effect of DE to the target insects. Also the treatment of wheat mixed with diatomaceous earth was contained the adult of tested pests, with the dose of 100 Gy would increase the mortality rate for these pests. So, the expected mortality was calculated at irradiation dose in the mixture with DE, concentration. Therefore, the expected mortality for the combination of two treatments was the sum of the mortalities of concentration and dose used is shown in Table (1). It is clear that, the two mixture types of irradiation dose with the tested DE concentration resulted in potentiation effect with co-toxicity factors (22.23 and 26.09) at two combination treatments against adult of T.castaneum.

Nearly similar result was recorded for the two combination types in case $R$. dominica. From data presented, in Table (1) which cleared the expected mortality percentage observed mortality percentage that co-toxicity factors exhibited, additive and potentiation effects, (18.00 and 38.46). On the other hand, the joint action of two treatments mixtures when was tested against $S$. granariusL. adults we observed that produced antagonistic effect, where the Co-toxicity factor values were $(-32.54$ and -27.42$)$. 


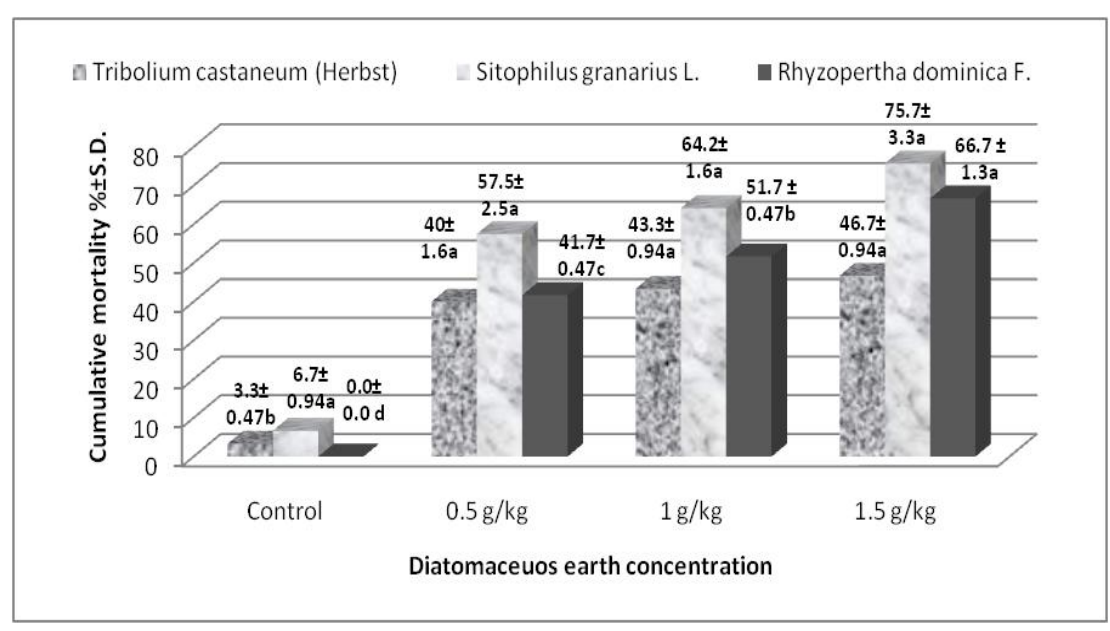

Figure (2): Effect of diatomaceous earth treatment on cumulative mortality percentages of different stored products pests at $7^{\text {th }}$ day

Combination methods are a good idea to deal with some disadvantages of one or more of these methods. Initially, we tested binary mixtures of Gamma irradiation doses and Diatomaceous earth concentrations. The toxicity tests using the pair wise combinations of two treatments were necessary to understand any less than or greater than joint action that occurred.

Probit analysis of gamma-irradiation and diatomaceous earthcombination

In this experiment a probit analysis of the timemortality is used to compare the tolerance among insect species, to help identify a target treatment for large-scale testing or suggesting application. Table (2) shows that the two combination treatments affected the insects faster than each separated for all insects. Data indicated that S.granarius L was the most susceptible to combination treatments among tested insect pests. The median lethal time was 2.7 in the case of treatment with irradiation at a 100Gy + diatomaceous earth treatment at $1 \mathrm{~g} / \mathrm{kg}$ and 1.9 days in the case of treatment with diatomaceous earth at $1 \mathrm{~g} / \mathrm{kg}+$ gamma-irradiation at 100Gy treatments, respectively. While the T.castaneum was the most tolerant $\left(\mathrm{LT}_{50}=10.2\right.$ and 5.0 days $)$ in the case of same combination treatments, respectively. R.dominicaF showed moderate effect compared to the other insects. However, we note that the estimated median time values for R.dominica $(\mathrm{F}$.) were very close (4.2 and 2.6 days) in the case of treatment with irradiation at a 100 $\mathrm{Gy}+$ diatomaceous earth treatment at $1 \mathrm{~g} / \mathrm{kg}$ and the treatment with diatomaceous earth at $1 \mathrm{~g} / \mathrm{kg}+$ gamma-irradiation at 100Gy treatments, respectively. Data in Table (2) suggested that $\mathrm{LT}_{50}$ have a wide range of values and the combined treatments of gamma-irradiation and treatment with diatomaceous earth maybe were the most influencing factors reducing lifespan after treatments.

\section{Discussion}

Using diatomaceous earth as a grain protectant or for structural treatment has been registered in several countries. To overcome the obstacles in DEs use for grain protection, DEs are combined with other insect control methods having different mode of action. The insects desiccation caused with DEs associated with insecticidal activity caused with another method $[15,16]$

In this laboratory study, the combination between food grade diatomaceous earth and the irradiation the tested pests with 100Gy of gamma ray produced a potentiation interaction, except in the case of $S$. granarius $\mathrm{L}$ adults. We note that the previous works emphasized that the effects of diatomaceous earth listed a remarkable synergism effect against many pests when paired with other control methods. This result can be supported by the report of Bougharra et al. [17], which indicated that diatomaceous earth + essential oils mixture completely controlled the maize weevil Sitophiluszeamais M.

On the other hand, Kimet al. [18] reported that diatomaceous earth (DE) could be used successfully as a synergist for heating systems, against 
Table (1): Joint toxic action between 100Gy dose of gamma irradiation followed by diatomaceous earth treatment at $1 \mathrm{~g} / \mathrm{kg}$ concentration treatmentand vice versa treatmentagainst tested insects

\begin{tabular}{|c|c|c|c|c|c|}
\hline & Pest species & $\begin{array}{c}\text { Observed } \\
\text { mortality \% }\end{array}$ & $\begin{array}{c}\text { Expected } \\
\text { mortality \% }\end{array}$ & $\begin{array}{c}\text { Co- } \\
\text { toxicity } \\
\text { factor }\end{array}$ & $\begin{array}{l}\text { Joint action } \\
\text { effect }\end{array}$ \\
\hline $\begin{array}{c}\text { Gamma- } \\
\text { irradiation at } \\
100 G y+ \\
\text { diatomaceous }\end{array}$ & $\begin{array}{l}\text { Triboliumcastaneum }(\text { Herbst } \\
\text { Sitophilusgranarius } \mathrm{L}\end{array}$ & $\begin{array}{c}81.7 \pm 0.8 \\
88.3 \pm 3.19\end{array}$ & $\begin{array}{c}66.3 \\
130.9\end{array}$ & $\begin{array}{c}22.23 \\
-32.54\end{array}$ & $\begin{array}{l}\text { potentiation } \\
\text { antagonistic }\end{array}$ \\
\hline $\begin{array}{c}\text { earth } \\
\text { treatment at } \\
1 \mathrm{~g} / \mathrm{kg}\end{array}$ & Rhyzoperthadominica, F & $76.7 \pm 5.54$ & 65.00 & 18.00 & additive \\
\hline $\begin{array}{l}\text { Diatomaceous } \\
\text { earth }\end{array}$ & $\begin{array}{l}\text { Triboliumcastaneum }(\text { Herbst } \\
\text { SitophilusgranariusL }\end{array}$ & $\begin{array}{l}83.3^{\mathrm{a}} \pm 16.6 \\
95.0^{\mathrm{a}} \pm 12.3\end{array}$ & $\begin{array}{c}66.3 \\
130.9\end{array}$ & $\begin{array}{r}26.09 \\
-27.42\end{array}$ & $\begin{array}{l}\text { potentiation } \\
\text { antagonistic }\end{array}$ \\
\hline $\begin{array}{c}\text { gamma- } \\
\text { irradiation at } \\
100 \mathrm{~Gy}\end{array}$ & Rhyzoperthadominica, F & $90.0^{\mathrm{a}} \pm 5.8$ & 65.00 & 38.46 & potentiation \\
\hline
\end{tabular}

Table (2): Sub-lethal time's values for the three insects exposed to different treatments

\begin{tabular}{|c|c|c|c|c|c|}
\hline & & $\begin{array}{l}\text { Gamma- } \\
\text { irradiation } \\
\text { at 100Gy }\end{array}$ & $\begin{array}{c}\text { Diatomaceous } \\
\text { earth } \\
\text { treatment at } \\
1 \mathrm{~g} / \mathrm{kg}\end{array}$ & $\begin{array}{c}\text { Gamma- } \\
\text { irradiation at } \\
100 \mathrm{~Gy}+ \\
\text { diatomaceous } \\
\text { earth } \\
\text { treatment at } \\
1 \mathrm{~g} / \mathrm{kg} \\
\end{array}$ & $\begin{array}{c}\text { Diatomaceous } \\
\text { earth } \\
\text { treatment at } \\
1 \mathrm{~g} / \mathrm{kg}+ \\
\text { gamma- } \\
\text { irradiation at } \\
100 \mathrm{~Gy} \\
\end{array}$ \\
\hline \multirow{4}{*}{ Triboliumcastaneum(Herbst) } & $\mathbf{L T}_{50}$ (days) & $28.0^{\mathrm{a}} \pm 1.2$ & $11.5^{b} \pm 0.9$ & $10.2^{b} \pm 0.74$ & $5.0^{c} \pm 1.2$ \\
\hline & Slope \pm SE & $1.9 \pm 0.33$ & $1.5 \pm 0.15$ & $2.2 \pm 0.27$ & $4.12 \pm 0.23$ \\
\hline & $\begin{array}{c}\text { Goodness of } \\
\text { fit chi } \\
\text { squared } *\end{array}$ & 8.41 & 21.5 & 5.4 & 95.8 \\
\hline & $\mathbf{P}=$ & 0.07 & 0.0003 & 0.2 & $\mathbf{0 . 0}$ \\
\hline \multirow{4}{*}{ Sitophilusgranarius $\mathbf{L}$} & $\mathrm{LT}_{50}$ (days) & $8.4^{\mathrm{a}} \pm 0.6$ & $3.4^{b} \pm 0.6$ & $2.7^{b} \pm 0.4$ & $1.9^{b} \pm 0.1$ \\
\hline & Slope \pm SE & $2.4 \pm 0.19$ & $3.7 \pm 0.17$ & $3.7 \pm 0.16$ & $7.8 \pm 0.37$ \\
\hline & $\begin{array}{c}\text { Goodness of } \\
\text { fit chi } \\
\text { squared* }\end{array}$ & 1.2 & 10.9 & 14.2 & 30.4 \\
\hline & $\mathbf{P}=$ & 0.8 & 0.03 & 0.007 & 0.0 \\
\hline \multirow{4}{*}{ Rhyzoperthadominica, $\mathbf{F}$} & $\mathbf{L T}_{50}$ (days) & $70.9^{a} \pm 5.3$ & $5.7^{b} \pm 0.1$ & $4.2^{\mathrm{b}} \pm 0.7$ & $2.6^{\mathrm{b}} \pm 0.4$ \\
\hline & Slope \pm SE & $1.44 \pm 0.35$ & $2.8 \pm 0.18$ & $2.5 \pm 0.14$ & $7.1 \pm 0.33$ \\
\hline & $\begin{array}{c}\text { Goodness of } \\
\text { fit chi } \\
\text { squared* } \\
\end{array}$ & 4.4 & 32.9 & 3.3 & 29.0 \\
\hline & $\mathbf{P}=$ & 0.3 & $\mathbf{0 . 0}$ & 0.5 & $\mathbf{0 . 0}$ \\
\hline
\end{tabular}

Moreover,[19] mentioned that that the addition of the DE to isolates of entomopathogenic fungi, Metarhiziumanisopliae

M.and BeauveriabassianaB. increased the pathogenicityagainstTriboliumcastaneum(Herbst)., RhyzoperthadominicaF., and OryzaephilussurinamensisL.The combination of insecticidal materials has the advantages to increase efficacy by complementing the bioefficacy of the individual products and simultaneously lowering their doses onthe one hand, and broadening the spectrum of activity and reducing the chance of resistance development on the other hand. From previous studies, the organism response curves which come from two types of mixture models that are regarded to be widely applicable to mixture toxicity. The first of these initially called similar joint action [20] and now referred to as concentration addition [21], occurs when the response curves of the toxicants are parallel (slopes of the curves are equivalent). The second joint action model was initially termed independent joint action [20] and is now referred to as response addition [21]. An organism's tolerance to a mixture of toxicants with dissimilar modes of action may or may not be correlated. It is 
generally accepted that dissimilar chemicals (i.e., those with different modes of action) interact by the response addition model that predicts toxicity at less than simple concentration addition levels $[22,23,24]$. As we examined mixtures of the gamma irradiation and Food grade diatomaceous earth concentrations. Those (two type of control methods) act as a chemicals with dissimilar modes of action, it is appropriate that we have framed our presentation with regard to the response addition model of mixture toxicity. From the previously mentioned results, in addition to what we know and feel about this situation, that the simultaneous using of both methods might limit depending upon the mode of action of each because these two methods are antagonistic to each other. Thus we find that the use of 'control method' gamma irradiation in conjunction with diatomaceous earth could be a feasible strategic component in IPM of Rhyzoperthadominica,(Fabricius),Sitophilusgranar ius (Linnaeus) and Triboliumcastaneum (Herbst.) in which operational modality might be 'sequential'. This is by using the gamma irradiation before DE application. If the application of gamma irradiation has been successful in the eradication of pest population, DE prevents reinfestation again.

\section{References}

1-J.C. Lord, J.F. Campbell, J.D. Sedlacek, and P.V. Vail, In Field Manual of Techniques in Invertebrate Pathology; Lacey, L.A., Kaya, H.K., Eds.; Springer: Dordrecht, The Netherlands, pp. 677-693.( 2007).

2-D. Pimentel, 1991. In Ecology and Management of Food Industry Pests; Gorham, J.R., Ed.; Association of Official Analytical Chemists: Arlington, MA, USA, pp. 5-11. (1991).

3-P.A. Follett, M.H. Yang, K.H. Lu, and T.W. Chen, J.Form. Entomol., 27: 1-15.(2007).

4-S. Tandon, A. Singh, and S. Knaujia,J. Plant Prot. Res., 49: 280-282 (2009).

5-S. Gasemzadeh, A.S. Pourmirza, M.S. Safarligadeh, and M. Maroufpoor. J. Form. Entomol. 50 (2): 140145(2010).

6-B.H. Subramanyam, and R. Roesli, R., Inert dusts. In: Alternatives to Pesticides in Stored-Product IPM. Subramanyam, Bh. and Hagstrum, D. W., eds., Kluwer Academic Publishers, Dordreecht, pp. 321380.(2000).

7-Z. Korunic, In: Proceedings of DDD and ZUPP 2014 (ed. Korunic, J.): 261-273. (2014)
8-M.S. Abd-Alla, Isotope\&Rad.Res. 42(1): 953-(2010).

9-F.K. Abdel-Kawy, S.A. Mohamed, A.Kh. Soliman, J.Rad.Res.Appl.Sci. 4 (2):339-350(2011).

10-B.H. Subramanyam, N. Madamanchi, and S. Norwood,J.Form. Entomol. 91(1):280-286(1998).

11-N.G.Kavallieratos, C.G. Athanassious, M.P. Michalaki, Y.A. Batta, H.A. Rigatos, F.G. Pashalidou, G.N.Balotis, Z.Tomanovic, and B.J. Vayias, J.Crop Prot.25(10):1087-1094(2006).

12-Y.P.Sun, and E.R. Johnson, J.Agr.Food. Chem., 8: 261 -266. ( 1960).

13-W.S. Abbott,1925. A method of computing the effectiveness of an insecticide. J. Econ. Entomol. 18: 265-267(1925).

14- D.J. Finney. Probit Analysis. 3rd ed. Cambridge University Press, London, 1971, 318.

15-R. Almaši, D. Poslončec and Z. Korunić, J. Agric. Sci., 19: 1076-1084. (2013).

16-V. Rozman, Z. Korunić, J. Halamić, A. Liška, R. Baličević, I. Galović, and P. Lucić. (in Croatian). Proceedings of the 27th Scientific and Educational Seminar DDD and ZUPP 2015 Disinfection, Disinfestation and Deratization and Protection of Stored Agricultural Products, Zagreb, Croatia: 197201. (2015)

17-H.H. Bougherra-Nehaoua, S. Bedini, F. Cosci, G.Flamini, K. Belhamel, and B. Conti, Enhancing the insecticidal efficacy of inert dusts against stored food insect pest by the combined action with essential oils. Integrated Protection of Stored Products IOBCWPRS Bulletin. 111: 31-38(2015)

18-H. Kim, Y. Su-YU, and K.Y. Kyeong-Yeoll LEE,.J.Entomol. Res. 44, 130-136. (2014)

19-Y. Shafighi, M. Ziaee, and Y. Ghosta,.J. Plant Prot.Res. 54 (1):62-65 (2014)

20-C.I. Bliss,.Ann Appl. Biol. 26 (3):585-615 (1939)

21-P.D. Anderson, and L.D. Weber,. The toxicity to aquatic populations of mixtures containing certain heavy metals. Proceedings, International Conference on Heavy Metals in the Environment, Toronto, ON, Canada, October 27-31, pp. 933-953. (1975)

22-S.J. Broderius,. Modeling the joint toxicity of xenobiotics to aquatic organisms: Basic concepts and approaches. In M.A.Mayes and M.G. Barron, eds., Aquatic Toxicology and Risk Assessment, Vol. 14. STP 1124. American Society for Testing and Materials, Philadelphia, PA, pp. 107-127(1990)

23-D.A. Dawson, and T.S. Wilke,.Environ. Toxicol. Chem. 10: 941-948(1991)

24-S. J. Broderius, M.D.Kahl, and M. D. Hoglund, M.D. Environ. Toxicol.Chem. .9:1591-1605(1995) 